\title{
O CONCEITO DE SUBJETIVIDADE NO SISTEMA DE HEGEL: A SUBJETIVIDADE ANIMAL NA NATUREZA E A PASSAGEM PARA A ALMA NA FILOSOFIA DO ESPÍRITO
}
THE NOTION OF SUBJECTIVITY IN THE HEGEL SYSTEM: THE ANIMAL SUBJECTIVITY IN NATURE AND THE TRANSITION TO THE SOUL IN THE PHILOSOPHY OF SPIRIT

\author{
Júlia Sebba Ramalho Morais ${ }^{1}$ \\ Recebido em: 04/2020 \\ Aprovado em: 11/2020
}

\begin{abstract}
Resumo: Neste artigo, investigo o conceito de subjetividade em Hegel. Em primeiro lugar, analiso essa noção em sua significação lógica, como conceito e como ideia, unidade da subjetividade e objetividade. Em segundo lugar, percorro a significação do conceito de subjetividade também na Filosofia do Real. Assim, abordo a subjetividade como vida, em sua concretização como subjetividade vegetal e como subjetividade animal na Filosofia da Natureza. Em seguida, problematizo a questão da passagem da Natureza para o Espírito, me centrando, mais especificamente, na questão da emergência da alma humana - enquanto primeiro aspecto da subjetividade do espírito - a partir da configuração da subjetividade animal. Defendo que esta passagem se dá segundo um movimento de continuidade e, a partir deste movimento, teço breves considerações sobre o conceito de alma enquanto o momento natural da subjetividade do espírito.

Palavras-chave: subjetividade, conceito, natureza, espírito, alma.
\end{abstract}

\begin{abstract}
In this article, I investigate the concept of subjectivity in Hegel. First, I analyze this notion in its logical significance, as a concept and as an idea, a unity of subjectivity and objectivity. Second, I go through the significance of the concept of subjectivity also in the Philosophy of Real. Thus, I analyze subjectivity as life, in its concretization as vegetable subjectivity and as animal subjectivity in the Philosophy of Nature. Then, I problematize the question of the passage from Nature to Spirit, focusing more specifically on the issue of the emergence of the human soul - as the first aspect of the subjectivity of the spirit - based on the configuration of animal subjectivity. I argue that this passage takes place according to a movement of continuity and, from this movement, I have brief considerations about the concept of soul as the natural moment of the subjectivity of the spirit.
\end{abstract}

Keywords: subjectivity, concept, nature, spirit, soul.

Falar de subjetividade (Subjektivität) na filosofia de Hegel pode ser tarefa difícil, uma vez que trata-se de um conceito vasto que percorre todas as três partes do sistema (Lógica,

\footnotetext{
${ }^{1}$ Professora Assistente do Curso de Filosofia da Regional Goiás (UFG -Universidade Federal de Goiás). Doutoranda em Filosofia pela FAFIL (UFG).
} 
Natureza e Espírito). Antes ainda de abordar a subjetividade na Natureza e no Espírito, Hegel trata do tema em sua Ciência da Lógica e, a meu ver, nesta obra, temos a gênese do conceito hegeliano de subjetividade. Na Lógica, não se trata ainda, contudo, da subjetividade em termos reais, ou seja, da subjetividade vital (própria da natureza), ou do espírito (Geist) subjetivo, o qual se manifesta como alma (Seele), consciência, pensamento e vontade. De outro modo, o contorno que Hegel confere à sua noção de subjetividade na Lógica se dá em termos formais, de maneira que, a partir desta noção, pode-se compreender os conceitos reais de subjetividade que se manifestam posteriormente na Natureza e no Espírito. Por conseguinte, antes mesmo de analisar como ocorre a manifestação da subjetividade vital na natureza - especificamente no reino das plantas e dos animais - e como, a partir da configuração desta realidade subjetiva, a alma emerge no terreno do espírito, irei tratar, de modo geral, da significação lógica do conceito de subjetividade que, consiste, para mim, na forma universal pertinente a todos os demais modos de manifestação subjetiva, já que a Lógica possui a função sistemática de estabelecer as condições formais e puras do pensamento pertinente ao real.

\section{A gênese lógica do conceito de subjetividade}

Na Lógica, Hegel trata da subjetividade como a natureza própria do conceito (Begriff). Segundo ele: "O conceito, na medida em que progrediu para uma existência tal que é, ela mesma, livre, nada mais é do que o Eu ou a autoconsciência pura" (Hegel, 2018, p. 44). Para Hegel, como pode-se depreender desta afirmação, a estrutura do conceito equivale formalmente à estrutura própria da subjetividade. Em minha visão, esta tese hegeliana se desenvolve a partir da interpretação crítica de Hegel a respeito da filosofia kantiana, uma vez que Hegel afirma logo no início de sua "Doutrina do Conceito" da Ciência da Lógica que "Uma das intelecções mais profundas e corretas que se encontram na Crítica da razão pura é a de que a unidade que constitui a essência do conceito é conhecida como a unidade originária sintética da apercepção, como unidade do "eu penso", ou da autoconsciência" (Hegel, 2018, p. 45). Um pouco mais à frente, Hegel ainda afirma: “A partir disso, uma proposição principal da filosofia kantiana justifica o fato de lembrar a natureza do Eu a fim de conhecer o que é o conceito" (Hegel, 2018, p. 46).

Não me cabe aqui adentrar nas especificidades do argumento kantiano sobre o tema 
exposto em sua "Dedução Transcendental das Categorias"2. Contudo, cumpre destacar apenas que, segundo Alfred Ferrarin, Hegel não interpretou corretamente o sentido do texto kantiano em questão, dado que, conforme Ferrarin, Kant não identifica a unidade originária da apercepção, ou seja, a autoconsciência, com o conceito. Antes, sustenta o autor italiano, Kant jamais proclama a identidade entre o eu e o conceito em sua filosofia; diferentemente, para Kant, há uma nítida diferença entre os dois, dado que a autoconsciência apenas fundamenta a unidade dos conceitos e a síntese operada por eles (Cf. FERRARIN, 2019, p. 142-143). Mas, penso, entretanto, que Hegel baseou-se no argumento de Kant a respeito da apercepção pura a fim de elaborar a sua própria concepção acerca do conceito lógico e da subjetividade. A este respeito, Robert Pippin, por sua vez, afirma, em sua obra Hegel's Realm of Shadows (2019), que Hegel sustenta que a unidade do conceito é a unidade da apercepção pura, ou da autoconsciência e, neste sentido, para Hegel, conforme Pippin, a estrutura e o autodesenvolvimento do conceito consistem na estrutura e no autodesenvolvimento da autoconsciência em um sentido kantiano (Cf. PIPPIN, 2019, p. 125).

A partir destas breves considerações, é interessante ressaltar que na primeira grande parte de sua "Doutrina do Conceito", no "Conceito Subjetivo", Hegel irá abordar a estrutura conceitual como uma interioridade ideal autorreferente. Mas, o que significa propriamente estas determinações e em que medida elas coincidem com as determinações do eu e, de modo geral, da subjetividade, uma vez que Hegel proclama a identidade entre o eu e o conceito lógico? Primeiro de tudo, é necessário esclarecer que tais determinações do conceito subjetivo não são simplesmente anexadas a ele de maneira externa, mas, diferentemente, são auto-produzidas por todo o curso da Ciência da Lógica, desde as categorias lógicas anteriores ao conceito até atualizarem-se nele. Assim, o conceito, concebido como sujeito, caracteriza-se como interioridade e, neste sentido, ele não se encontra posto na exterioridade como um ser ao lado dos outros. A interioridade do conceito, entretanto, não é dada prontamente a ele. Na "Doutrina da Essência"”, já tínhamos o momento da interioridade (Innerlichkeit); contudo lá ela se punha como oposta à exterioridade (Äusserlichkeit) e ambas se encontravam, pois, em uma relação de oposição, de modo que se mostravam apenas como "lados" diferentes da unidade da efetividade. No conceito, entretanto, a interioridade passa por um processo mais complexo, pois

\footnotetext{
${ }^{2} \mathrm{Na}$ "Dedução Transcendental das Categorias" de sua Crítica da Razão Pura, Kant pretende deduzir a validade objetiva dos conhecimentos. Para tanto, Kant afirma que os conceitos fundam a sua unidade sintética na unidade da apercepção pura, ou autoconsciência pura (Cf. KANT, 2010, B 136). É no contexto deste argumento que Hegel retira sua tese da identidade entre a unidade do conceito e da subjetividade.

${ }^{3}$ A Ciência da Lógica de Hegel se divide em "Doutrina do Ser" e "Doutrina da Essência", que compreendem a "Lógica Objetiva" e "Doutrina do Conceito", que consiste na "Lógica Subjetiva".
} 
que o conceito é aquele que retornou para dentro de si por um movimento de negação da exterioridade e, por conseguinte, ele é para si (für sich) no sentido de se referir a si mesmo $(S e l b s t)^{4}$. Assim, esta atividade negativa de voltar-se para si mesmo é, na verdade, uma atividade reflexiva e é por ela que funda-se, pois, a interioridade do conceito, que não se caracteriza, entretanto, como um lugar interno em oposição ao externo, mas, sim, como uma autorrelação, ou autorreferência. A interioridade do conceito, portanto, configura-se como um auto-movimento reflexivo, no qual podemos vislumbrar a atividade universal de autorreferência do eu em sua identidade.

Com efeito, esta autorreferência interior do conceito, ou do eu ${ }^{5}$, consiste precisamente na forma de sua universalidade. Hegel define o conceito segundo três aspectos essenciais, que são eles: a universalidade (Allgemeinheit), a particularidade (Besonderheit) e a singularidade (Einzelnheit). $\mathrm{O}$ aspecto de sua universalidade diz respeito à sua autorreferência negativa, ou seja, à capacidade do conceito e do eu de se abstraírem de toda a exterioridade e se porem em unidade consigo de modo universal, sem se ligar a nada de particular.

Portanto, o conceito é primeiramente a identidade absoluta consigo, de modo que ela é isso somente enquanto é a negação da negação, ou seja, a unidade infinita da negatividade consigo mesma. Essa relação pura do conceito consigo, a qual é essa relação pelo fato de que se põe através da negatividade, é a universalidade do conceito (Hegel, 2018, p. 66).

O aspecto da universalidade do conceito, entretanto, não se põe simplesmente como uma determinação ao lado das determinações da particularidade e da singularidade. Isso porque, para Hegel, o conceito, como totalidade subjetiva, engloba em seu interior como reciprocamente referentes os seus três aspectos. Assim, Hegel afirma a respeito dos três momentos do conceito: "cada um deles é a totalidade, cada um contém a determinação do outro dentro de si, e, por isso, essas totalidades também são pura e simplesmente apenas uma” (Hegel, CL, 2018, p. 43).

\footnotetext{
${ }^{4} \mathrm{Na}$ Ciência da Lógica, o primeiro momento de "interiorização" das categorias lógicas ocorre com o ser-para-si (FÜrsichsein) que, a partir da exterioridade do ser-aí (Dasein), retorna sobre si mesmo. Não temos aqui ainda a noção de conceito, ou de subjetividade, completamente desenvolvida, contudo, Hegel já chega a afirmar que "O exemplo mais próximo do ser-para-si temos no Eu” (Hegel, 2005, § 96, adendo).

${ }^{5}$ Similarmente, na "Introdução" da Filosofia do Direito - que, ainda que seja uma obra à parte, situa-se no interior do "Espírito Objetivo" da Filosofia do Espírito - Hegel irá descrever as determinações fundamentais do conceito de vontade pensante, ou do eu prático. Neste texto, em minha visão, Hegel trata das determinações do eu em um sentido lógico puramente formal, dado que não abarca ainda em sua análise questões e elementos particulares referentes à concretização da vontade no mundo do Direito. Desse modo, é interessante notar que há uma intercorrespondência lógico-real entre a análise de Hegel acerca do conceito subjetivo na "Doutrina do Conceito" da Ciência da Lógica e de sua análise do eu prático na "Introdução" da Filosofia do Direito.
} 
A particularidade e a singularidade do conceito, desse modo, são postas pelo conceito mesmo no interior de sua universalidade em um profundo movimento interno de auto e interconexão que compõe a totalidade universal da estrutura subjetiva do conceito.

\begin{abstract}
Mas, não se pode falar do universal sem a determinidade, a qual, mais precisamente, é a particularidade e a singularidade; pois ele a contém em si e para si dentro de sua negatividade absoluta; a determinidade não é, portanto, tomada desde fora quando dela se fala junto ao universal. Enquanto negatividade em geral, ou seja, conforme a negação primeira, imediata, ele tem a determinidade em geral enquanto particularidade nele; enquanto, segundo, como negação da negação, ele é determinidade absoluta ou singularidade e concreção (Hegel, 2018, p. 69).
\end{abstract}

O momento da particularidade é, pois, o momento da auto-diferença da subjetividade do conceito. Pela particularidade, o conceito se dá uma determinação, uma diferença; no caso do eu, se dá um conteúdo mental, seja ele teórico ou prático. Esta autodeterminação da particularidade, entretanto, sobressai-se de modo imanente da própria universalidade da subjetividade, e não como um particular que é simplesmente acrescentado ao universal.

Dada a similaridade conceitual entre a tematização de Hegel do momento da particularidade na "Doutrina do Conceito" e a sua abordagem formal da "Introdução" da Filosofia do Direito (ver nota 5 acima), convém citar uma passagem desta última: "O eu é, de outro modo, a passagem da indeterminação indiferenciada para a diferenciação, para a determinação, para a instauração de uma determinação que seja um conteúdo e um objeto, quer este conteúdo seja dado pela natureza, ou produzido a partir do conceito de espírito" (Hegel, 1993, § 6; daqui em diante, a tradução é minha). Como veremos ao longo do trabalho, este momento de determinação e auto-diferenciação é o momento preciso em que a subjetividade universal - seja ela a subjetividade do animal, ou mesmo do espírito, enquanto alma - põe para si um conteúdo determinado, quer seja um instinto, ou um conteúdo sensitivo, por exemplo, e se afirma para si em unidade com este conteúdo.

Além disso, o conteúdo próprio concernente ao momento da particularidade consiste em uma determinação ideal. Ou seja, não é o caso que a subjetividade do conceito, ou do eu, assimile realmente em seu interior algum elemento externo particular. Antes, ocorre apenas uma assimilação ideal, de modo que o elemento exterior existe somente idealmente no interior da universalidade da subjetividade. Assim, a determinação da idealidade (Idealität) consiste em uma característica fundamental para compreendermos corretamente a definição de Hegel acerca do contorno da subjetividade em seus aspectos de universalidade, particularidade e 
singularidade.

Na Ciência da Lógica, Hegel trata da determinação da idealidade já na "Doutrina do Ser", antes mesmo de adentrar na "Doutrina do Conceito", mas a idealidade consiste, a meu ver, em uma determinação já "proto-subjetiva”, uma vez que, posteriormente, encontramo-la novamente no "Conceito", como uma determinação fundamental para a afirmação da interioridade da subjetividade lógica. Com efeito, na "Doutrina do Ser", Hegel afirma que a idealidade deve ser entendida como o contrário da realidade, pois que a idealidade refere-se à relação de suspensão (Aufhebung) ${ }^{6}$ que, no caso, o ser-para-si promove em relação à exterioridade. "No ser-para-si é introduzida a determinação da idealidade. O ser-aí, inicialmente apreendido apenas segundo seu ser ou sua afirmação, tem uma realidade; assim, a finitude, de início, também está na determinação da realidade. Mas a verdade do finito é, antes, sua idealidade" (Hegel, 2005, § 95). Desse modo, o ser que encontra-se posto completamente na exterioridade, ou seja, o ser-aí, está no modo da realidade e encontra-se limitado por outros seres, que mostram-se como sua barreira, como sua limitação. Com o retorno para dentro de si, entretanto, o ser liberta-se de seus limites externos e todo elemento externo torna-se, para ele, então, ideal. Em outras palavras: o ser idealiza em seu interior os elementos exteriores que, antes, configuravam para ele como limites. Também na Filosofia do Espírito Subjetivo Hegel fala a respeito da idealidade do espírito:

Essa suprassunção da exterioridade - suprassunção que pertence ao conceito do espírito - é o que temos chamado sua idealidade. Todas as atividades do espírito nada são a não ser maneiras diversas da recondução do que é exterior, à interioridade que é o espírito mesmo; e só mediante essa recondução, mediante essa idealização ou assimilação do exterior, vem a ser, e é, o espírito. Ao considerar o espírito um pouco mais de perto, encontramos, como sua determinação primeira e mais simples, a determinação de que é [um] Eu (Hegel, 1995, $\S 381$, adendo; o grifo é meu).

Como se vê, a idealidade consiste precisamente nesta atividade de assimilação dos elementos da exterioridade para a interioridade e ela é constitutiva não somente da estrutura especulativa do conceito subjetivo, do eu e do espírito de modo geral, mas também, como veremos mais à frente, do próprio conceito de vida na natureza e também da existência subjetiva

\footnotetext{
${ }^{6}$ Utilizo aqui o termo "suspender" para traduzir aufheben seguindo a indicação de José Pertille que utiliza "suspender" a partir de uma sugestão de Dennis Rosenfield (Ver Pertille, 2005, p. 65). Nas traduções brasileiras que utilizo da Ciência da Lógica e da Enciclopédia, contudo, utiliza-se o termo "suprassumir". Com efeito, aufheben possui uma tripla acepção, a saber: (a) a de conservar algo, (b) de negar e (c) de elevar.
} 
das plantas e dos animais. Na Filosofia da Natureza, na seção sobre "O Organismo Animal”, Hegel afirma que o animal também se relaciona, assim como as plantas, com o outro como com a um ideal (Cf. HEGEL, 1997, § 351, adendo). Todavia, acrescenta ele, nas plantas este comportamento se dá somente de modo prático, de modo que as mesmas, por exemplo, assimilam completamente seu outro (a luz, por exemplo). Já os animais, também o deixam subsistir, na medida em que também mantêm com o outro um comportamento teórico através da sensação e, assim, os animais sentem em seu interior alguns conteúdos - como, por exemplo, a dor - e se mantêm em unidade com eles.

Justamente esta unidade com e a partir de sua determinação particular, ou de seu conteúdo, configura a subjetividade do conceito em seu último momento, como singularidade. O momento da singularidade é, assim, a unidade da universalidade com a particularidade. E, mais uma vez, para bem ilustrar a significação deste terceiro e último aspecto da subjetividade, recorro ao texto da "Introdução" da Filosofia do Direito:

\begin{abstract}
A vontade é a unidade destes dois momentos: ela é a particularidade refletida sobre si e por isso reconduzida ao universal, ou a singularidade. Ela é a autodeterminação do eu, operação que consiste, para ele, ao mesmo tempo, em seu pôr como o negativo de si mesmo, quer dizer, como determinado e limitado e, ainda, permanecer junto de si, quer dizer, em sua identidade consigo e em sua universalidade, portanto, na determinação, não permanecer senão consigo mesmo (Hegel, 1993, §7; o grifo é meu).
\end{abstract}

O momento da singularidade é, pois, o momento especulativo, aquele que unifica duas determinações aparentemente opostas, mas que, entretanto, na visão de Hegel, se mostram como interligadas. O termo "especulativo" na filosofia de Hegel possui uma significação muito importante. Conforme ele, todo elemento lógico - e também todo elemento real - possui três lados que devem ser considerados sempre em sua inter-ligação ${ }^{7}$. O primeiro lado é o do entendimento e, por ele, concebe-se as coisas em sua determinidade fixa, separadas umas das outras e, dessa maneira, cada determinação, segundo o modo de conceber do entendimento, permanece como um abstrato frente às outras (Cf. HEGEL, 2005, § 80). Permanecer apenas neste modo de conceber o elemento lógico e também o elemento da realidade, significa, por exemplo, compreender a subjetividade não como uma totalidade única e singularmente especulativa - como consta acima na passagem citada do parágrafo 7 da Filosofia do Direito -

\footnotetext{
7 "A lógica tem, segundo a forma, três lados: a) o lado abstrato ou do entendimento; b) o dialético ou negativamente racional; c) o especulativo ou positivamente racional. Esses três lados não constituem três partes da Lógica, mas são momentos de todo [e qualquer] lógico-real, isto é, de todo conceito ou de todo verdadeiro em geral" (Hegel, 2005, § 79).
} 
mas, sim, como se a universalidade se encerrasse como separada de sua particularidade e a subjetividade fosse, pois, cindida em si mesma ${ }^{8}$.

O segundo lado de todo elemento lógico-real é o dialético e ele consiste precisamente na suspensão de determinações opostas e no movimento de sua articulação (Cf. HEGEL, 2005, $\S 81)$. E o terceiro lado, por fim, é justamente aquele do especulativo, que "apreende a unidade das determinações em sua oposição" (Hegel, 2005, § 82). O momento do especulativo é o momento da razão e do absoluto, pois que é o absolutamente concreto, unidade da subjetividade com a objetividade.

Assim, com base nestas considerações sobre a natureza especulativa da subjetividade lógica, cumpre-me mostrar, enfim, que o conceito, para Hegel, é visto como subjetivo, porém, como subjetivo em sua significação absoluta, dado que ele se põe em unidade com a objetividade e é, desse modo, o princípio de toda a realidade.

O ponto de vista do conceito é, de modo geral, o do idealismo absoluto, e a filosofia é um conhecimento conceituante (...). Na lógica-de-entendimento, costuma-se considerar o conceito como uma mera forma do pensar, e, mais precisamente, como uma representação geral. É a essa maneira inferior de apreender o conceito que se refere a afirmação tantas vezes repetida, por parte da sensibilidade e do coração, de que os conceitos enquanto tais são algo morto, vazio e abstrato. De fato porém sucede exatamente o inverso, e o conceito é antes o princípio de toda a vida, e assim ao mesmo tempo, o [que é] pura e simplesmente concreto (Hegel, 2005, § 160, adendo; o grifo é meu).

Hegel afirma primeiramente na passagem acima que o ponto de vista do conceito é o do Idealismo Absoluto9 . Isso porque o conceito, na visão de Hegel, suspendeu (aufheben) a oposição entre a subjetividade e a objetividade e comporta, pois, uma unidade absoluta entre ambos. Assim, o conceito, conforme Hegel, subjaz a todo real e é, portanto, ideia.

A ideia é o verdadeiro em si e para si, a unidade absoluta do conceito e da objetividade. Seu conteúdo ideal não é outro que o conceito e suas determinações, seu conteúdo real é somente a exposição do conceito, que ele se dá na forma do ser-aí exterior, e estando sua figura excluída na idealidade

\footnotetext{
${ }^{8}$ Para Hegel, com efeito, as filosofias kantiana e fichtiana concebem a natureza da subjetividade segundo o entendimento. Pois, conforme Hegel, elas permanecem na consideração da oposição da universalidade com a particularidade do conteúdo e do não-eu (Cf. HEGEL, 1993, § 6).

${ }^{9} \mathrm{Na}$ Filosofia da Natureza Hegel afirmará que "a vida do animal é assim, como este ponto mais alto da natureza, $o$ idealismo absoluto, é ter em si juntamente, numa maneira perfeitamente fluida, a determinidade de sua corporeidade - é anexar e incorporar, e tê-lo incorporado - ao subjetivo esse imediato" (Hegel, 1997, § 350, adendo). Nesta passagem, Hegel está falando que o animal liga-se à natureza inorgânica e ao mundo exterior. Todavia, permanece, neste mundo exterior como um universal em identidade consigo. Também a respeito da vida, considerada abstratamente, Hegel irá afirmar no parágrafo 337 que sua existência corresponde ao Idealismo Absoluto.
} 
do conceito, na sua potência, assim se conserva na ideia (Hegel, 2005, § 213).

A ideia se mostra no interior da Lógica de Hegel como um auto-desdobramento do conceito lógico subjetivo e ela pode ser compreendia, segundo Hegel, como razão, unidade de sujeito e objeto, unidade do ideal e do real, do finito e do infinito, da alma e do corpo (Cf. HEGEL, 2005, § 214). É a partir do contexto da ideia, portanto, que devemos entender retrospectivamente a noção hegeliana de conceito. Pois que o conceito, como subjetividade lógica, deve ser compreendido em unidade com a objetividade e não como isolado e em oposição a ela. Da mesma maneira, as formas reais de subjetividade tratadas por Hegel na Filosofia da Natureza e na Filosofia do Espírito, deverão ser assim compreendidas. Para Hegel, a oposição entre sujeito e objeto, ou mais especificamente, entre autoconsciência e objeto fora superada em sua Lógica a partir do desenvolvimento de sua Fenomenologia do Espírito de $1807^{10}$.

Por conseguinte, no seu capítulo sobre a "Ideia", Hegel aponta para as formas de subjetividade consideradas concretamente que posteriormente desenvolver-se-ão em sua Filosofia do Real. No capítulo sobre a "A Vida", encontramos a primeira forma de subjetividade que se desenvolve a partir do auto-desdobramento do lógico do conceito em ideia. Este capítulo é amplamente discutido na literatura secundária, dado que constitui traço inusitado na História da Filosofia tratar sobre o conceito de vida no interior de uma Lógica. Segundo Diogo Ferrer, o conceito de "vida" possui uma centralidade no interior da Lógica de Hegel. Entretanto, o autor guarda, com as devidas proporções, as diferenças entre a tematização da vida na Lógica daquela feita na Filosofia da Natureza (Cf. FERRER, 2016, p. 131-132) ${ }^{11}$. O próprio Hegel explicita esta diferença e afirma:

A primeira, enquanto vida da natureza, é a vida que está lançada para fora na exterioridade do subsistir, tem sua condição na natureza inorgânica e os momentos da ideia são uma multiplicidade de configurações efetivas. A vida

\footnotetext{
10 “A pura ciência pressupõe, com isso, a libertação da oposição da consciência. Ela contém o pensamento, na medida em que ele é igualmente a Coisa em si mesma, ou seja, a Coisa em si mesma, na medida em que ela é igualmente o pensamento puro. Como ciência, a verdade é a pura autoconsciência que se desenvolve e tem a figura do Si (Selbst), a saber, que o ente em e para si é o conceito sabido, mas o conceito enquanto tal é o ente em e para si” (Hegel, 2017, p. 52). Para Hegel, a partir da Lógica tem-se como superada a oposição do sujeito, enquanto autoconsciência cognoscente, com o objeto. Sua filosofia sistemática madura, deste ponto de vista, parte, de outro modo, da unidade entre ser e pensamento no interior do elemento puro lógico e, por conseguinte, também a subjetividade, tanto considerada logicamente (como estou abordando neste tópico), como considerada sob seu aspecto natural, ou espiritual, deve ser tratada em unidade com o objeto, de maneira, que o momento de sua oposição só possa ser pensado desde que se parta desta unidade originária.

${ }^{11}$ Vittorio Hösle problematiza o fato de a vida ser tratada no interior da Lógica de Hegel. Ver HÖSLE, 2007, p. 271-282.
} 
na ideia é sem tais pressuposições que são como figuras da efetividade; sua pressuposição é o conceito, tal como ele foi considerado, por um lado, como subjetivo, por outro lado, como objetivo. Na natureza, a vida aparece como o estágio supremo que é alcançado por sua exterioridade pelo fato de que essa se interiorizou e se suprassume na subjetividade. Na lógica, é o ser dentro de si simples, que na ideia da vida alcançou sua exterioridade que lhe corresponde veridicamente; o conceito que apareceu anteriormente como subjetivo é a alma da própria vida; ele é o impulso que medeia sua realidade através da objetividade (Hegel, CL, 2016, p. 246).

Para Hegel, há nitidamente uma diferenciação em termos sistemáticos, ou, mais precisamente, em termos de localização, entre a ideia da vida e a vida real da Filosofia da Natureza. Não me cabe aqui entrar nesta problematização, que foge ao meu propósito. O que quero apenas destacar é que $\left(1^{\circ}\right)$ a ideia da vida lógica abarca o conceito, 'tal como ele foi considerado, por um lado, como subjetivo, por outro lado, como objetivo'; ou seja, a vida lógica é subjetividade e $\left(2^{\circ}\right)$ que 'Na natureza, a vida aparece como o estágio supremo que é alcançado por sua exterioridade pelo fato de que essa se interiorizou e se suprassume na subjetividade'; ou seja, na Filosofia da Natureza, a vida, ainda que esteja no elemento da exterioridade natural, alcançou sua interioridade. Irei abordar um pouco mais detalhadamente o conceito de vida em sua subjetividade no tópico seguinte.

Mas, antes disso o que quero ainda destacar é que após o capítulo sobre "A Vida", no capítulo sobre "A ideia do Conhecer", Hegel aponta ainda para a sua concepção sobre o conceito especulativo de espírito. O espírito se divide em "Espírito Subjetivo", "Objetivo" e “Absoluto". Mas, o que me importa no presente artigo é abordar apenas a subjetividade do espírito que, por sua vez, se divide ainda em alma, consciência e vontade pensante. Tratar de todas estas faces desta subjetividade também fugiria ao meu propósito. Desse modo, o que quero frisar mais particularmente é que o primeiro aspecto da subjetividade do espírito é aquele da alma e esta se mostra, pois, não como alma no sentido da Antiga Metafísica criticada por Hegel, mas, sim, como alma no sentido profundamente natural do termo, na medida em que ela se encontra em intrínseca unidade com o corpo e que emerge da Natureza (Cf. HEGEL, 1995, $\S 389)$.

Nesta perspectiva, parto da consideração de Hegel de que há uma circularidade e uma continuidade profunda em sua filosofia em suas três partes, a saber: Lógica, Natureza e Espírito. Na Lógica da Enciclopédia Hegel já alude para esta caracterização de que "um filosofar sem sistema não pode ser algo científico” (Hegel, 2005, § 14) e, ademais, que a filosofia, como um todo, "se apresenta como um círculo de círculos" (Hegel, 2005, § 15). De modo que, para mim, o conceito de subjetividade, que possui sua gênese na Lógica como conceito lógico subjetivo 
que torna-se ideia concreta (como acabamos de ver), permeia o todo filosófico em sua sistematicidade circular, afirmando-se em cada pequeno círculo sob uma faceta que, entretanto, não se desliga da outra. Consequentemente, a subjetividade lógica do conceito permanece como forma absoluta nas manifestações da subjetividade na Filosofia da Natureza (onde especificamente irei analisar a subjetividade vegetal e a animal) e na subjetividade da Filosofia do Espírito Subjetivo (onde especificamente irei analisar apenas a alma da "Antropologia", me centrando mais particularmente sobre sua emergência a partir da subjetividade animal).

\section{O conceito de vida e a subjetividade natural}

Podemos iniciar nosso estudo sobre conceito vital de subjetividade na Filosofia de Hegel no parágrafo 337 da Filosofia da Natureza, onde Hegel tece importantes considerações sobre o conceito de vida e o de organismo. Aí, afirma que a ideia chegou à existência, primeiramente imediata, como vida e é, assim, "uma elevação à primeira idealidade da natureza" (Hegel, 1997, § 337). Ora, para Hegel, a vida contém a determinação da idealidade (Idealität), ou seja, a capacidade de suspender (aufheben) o dado externo para sua interioridade, idealizando-o, dissolvendo-o em seu interior em unidade consigo, como vimos acima a respeito do conceito lógico. Esta capacidade só é possível plenamente no interior da subjetividade e, assim, Hegel prossegue afirmando: "mas [uma elevação] de tal modo que ela se tornou uma unidade saturada [erfüllte] e essencialmente, enquanto a si referindo-se, unidade negativa, com a forma de Si [Sebstische] e subjetiva" (idem; o grifo é meu). Na sequência de todo este parágrafo, Hegel irá analisar o conceito de vida segundo a caracterização de sua subjetividade. Segundo ele, a principal determinação da vida é a subjetividade. Consequentemente, com a chegada do vivo no contexto do desenvolvimento da natureza - desde as determinações de espaço e tempo na Mecânica - a subjetividade encontra-se, então, em condições de emergir e se consolidar ${ }^{12}$.

Mas, por que, propriamente, a vida é o terreno próprio para que a subjetividade se manifeste? Quais são, pois, para Hegel, suas características que possibilitam a formação da subjetividade?

\footnotetext{
${ }^{12}$ A natureza, para Hegel, é desenvolvimento da ideia e, segundo ele, não deve ser vista estritamente em termos evolutivos, tampouco de emanação. Ver $\S 249, \S 250$ e $\S 251$. Para Hegel, há uma finalidade intrínseca na natureza e o conceito, segundo ele, põe e movimenta este fim de realização da natureza. "A natureza é para considerar-se como um sistema de [estágios ou] degraus dos quais necessariamente um procede do outro e é a verdade mais próxima daquele [degrau] do qual resulta; não porém de modo que um seja naturalmente gerado pelo outro, mas na ideia interna constitutiva do fundamento da natureza. A metamorfose só acontece no conceito como tal, pois só a alteração deste é desenvolvimento" (Hegel, 1997, § 249).
} 
De acordo com Hegel, a vida deve ser apreendida no elemento do especulativo, ou seja, ela não pode ser pensada como algo de real, como um objeto dado positiva e estaticamente no mundo exterior e que se encontraria em estado de oposição a outros elementos. De outro modo, a vida se expõe àquilo que a contradiz, suportando e dissolvendo esta diferença. Por isso: "o agir continuado da vida é assim o idealismo absoluto; ela torna-se um outro, o qual, porém, é suprassumido. Se a vida fosse realista, teria respeito diante do externo; mas ela obstrui sempre a realidade do outro e transforma-se a si mesma" (Hegel, 1997, § 337, adendo; o grifo é meu). Isso significa que a vida possui a característica da relação e do movimento dialético de unificação, pelo qual apreende o diferente a si, modificando-se também internamente e permanecendo, enfim, em unidade consigo. Cumpre destacar que nesta altura de seu argumento, Hegel está falando da vida no elemento da universalidade, ou seja, do conceito abstrato de vida, que deve se "encarnar" ainda nos organismos vivos propriamente falando, que são, por exemplo, as plantas e os animais. Desse modo, inúmeros são as figuras que podemos usar para ilustrar a situação do conceito universal de vida em sua atividade de suspensão da exterioridade: temos, no caso das plantas, a imagem da fotossíntese, pela qual, o vegetal assimila os elementos químicos presentes na atmosfera para se nutrir; no caso do animal, ele vai à caça para se saciar.

Mas, cabe ainda a pergunta: o que tais relações vitais têm a ver com o conceito de subjetividade? Ora, podemos notar que em todos estes contextos ocorre uma relação de interpenetração entre duas esferas que aparentemente podem se mostrar inconciliáveis: entre a existência concreta e corpórea do vivo (seja da planta, ou do animal) e a do mundo natural, ou da natureza inorgânica exterior. Assim, a vida só é vida, pois põe e, além disso, simultaneamente, relaciona os momentos da interioridade dos organismos vivos (plantas e animais) e da exterioridade; ou, em outras palavras, a vida inter-conecta e unifica, como ideia, a subjetividade e objetividade.

A vida é a união de oposições em geral, não somente da oposição do conceito $e$ da realidade. A vida é onde o interior, causa e efeito, fim e meio, subjetividade e objetividade etc. [tudo isso] é uma e a mesma coisa. A verdadeira determinação da vida é que pela unidade do conceito e da realidade, esta realidade não mais seja - de modo imediato, do modo da independência - como multidão de propriedades existentes e fora-umas-dasoutras, porém que o conceito simplesmente seja realidade do subsistir indiferente (Hegel, 1997, § 337, adendo; o grifo é meu).

A vida é, portanto, ideia que põe e articula momentos aparentemente opostos. Somente uma unidade em si mesma negativa, ou seja, algo que pode negar-se para assimilar o outro, 
pode pôr-se como interioridade subjetiva frente ao exterior e unificar-se com ele. E aqui estamos falando de interioridade não no sentido de uma instância, ou de um lugar reservado frente ao que lhe é externo; mas, sim, de interioridade no sentido de constituir uma autorrelação especulativa de si para consigo em mediação com a exterioridade, assim como vimos ser o caso com o conceito lógico. De outro modo, anteriormente à manifestação da vida na natureza, tínhamos apenas o elemento da exterioridade, do fora-um-do-outro, em que todas as relações se davam apenas em conexão exterior, sem nenhuma determinação e articulação interna. Dessa maneira, reinava na natureza relações tais que os elementos envolvidos apareciam como autônomos uns em relação aos outros, geridos por leis externas a eles. O sistema solar é um exemplo desta configuração, em que todos os planetas giram ao redor do sol sem nenhuma conexão interna (Cf. HEGEL, 1995, § 381, adendo) ${ }^{13}$.

No entanto, mesmo neste contexto anterior em que reinava a exterioridade, segundo Hegel, a própria natureza encontrava-se em uma luta incessante em busca da interioridade, em torno de um núcleo pelo qual pudesse encontrar-se em unidade consigo (Cf. HEGEL, 1995, § 381). Diante disso, podemos questionar: qual é a exata condição conquistada pela natureza que pôde possibilitar, enfim, a emergência da subjetividade pela vida? Pois, no grau dos elementos químicos, por exemplo, só podíamos encontrar relações fluidas externas, uma vez que tais elementos encontravam-se dispersos na natureza; no grau da natureza geológica, por seu turno, encontrávamos apenas o "fora-um-do-outro" dos seres, onde apenas a posição espacial de cada um era determinante.

No que toca ao conceito do subjetivo, a questão parece centrar-se sobre a existência do corpo vivo, que é, mais especificamente, a real condição material de emergência da subjetividade. A vida, considerada abstratamente, é o processo todo da natureza, o sistema total dos seres viventes; enquanto o organismo, por seu turno, é a encarnação concreta da vida, sua individuação corpórea. "A vitalidade como natural dispersa-se de fato na multiplicidade imediata de viventes, os quais, entretanto, são neles mesmos organismos subjetivos, e é somente na ideia que eles são uma vida, um sistema orgânico da mesma vida" (Hegel, 1997, § 337, adendo).

Hegel fala neste sentido no organismo como o material próprio sobre o qual a subjetividade viva se desenvolve e manifesta. Dessa forma, somente um corpo orgânico pode

\footnotetext{
${ }^{13}$ Conforme Hegel: "A natureza mostrou-se como a ideia na forma do ser-outro. Visto que a ideia é assim como o negativo dela mesma ou exterior a si, assim a natureza não é exterior apenas relativamente ante esta ideia (e ante a existência subjetiva da mesma, o espírito), mas a exterioridade constitui a determinação, na qual ela está como natureza" (Hegel, 1997, p. 26, § 247).
} 
ser pensado como subjetivo, pois, ao contrário, um corpo que é simplesmente uma soma de átomos, um corpo que é perfeitamente divisível, como uma pedra, é bruta exterioridade, onde cada parte é completamente exterior às demais e à soma total de seus componentes ${ }^{14}$. $\mathrm{O}$ organismo, por outro lado, é uma totalidade interna cíclica, onde cada ponto é completamente dependente e submetido ao todo e este, por sua vez, é a totalidade inter-penetrante de suas partes envolvidas. "O conceito abstrato do organismo é, ao contrário, que a existência das particularidades, enquanto estas são postas como existências passageiras de um sujeito, é comensurada na unidade do sujeito" (Hegel, 1997, § 337, adendo). Assim, o orgânico é puro movimento de si, ele "já é em si o que ele é efetivamente; ele é o movimento de seu vir-a-ser [devir]" (Hegel, 1997, § 337, adendo).

Com base nesta breve análise, podemos ponderar: se, como vimos, a subjetividade, para Hegel, começa com a vida, isso quer dizer que a planta já tem subjetividade? A resposta de Hegel é positiva, ainda que nas plantas não encontremos uma subjetividade propriamente dita, uma subjetividade concreta, realizada. Nesta linha, é interessante mostrar de quê maneira a articulação do corpo vivo do organismo vegetal, por um lado, e aquele do organismo animal, por outro, influencia diretamente na efetivação da subjetividade em cada um destes níveis. Nas plantas, uma vez que o conceito de organismo ainda não é totalmente efetivado, a subjetividade ainda será incipiente e nos animais, onde já podemos encontrar um corpo altamente desenvolvido, a subjetividade encontra seu ponto alto no interior do desenvolvimento da natureza. Vejamos ${ }^{15}$.

\section{Subjetividade nas plantas e no organismo animal}

No reino vegetal, ou no mundo das plantas, temos já, conforme Hegel, o início da subjetividade. Isso porque, conforme afirma, as plantas são já individualidade, e não apenas

\footnotetext{
${ }^{14}$ Ainda que, por exemplo, Hegel fale já de subjetividade em relação ao centro de gravidade (Cf. HEGEL, 1997, § 270) e também em relação aos planetas (Cf. HEGEL, 1997, § 280) é somente com o corpo vivo que temos efetivamente a condição de emergência efetiva do para-si (Selbst), pois que pelo corpo vivo, pode-se sentir. Tratase, ainda, de um para-si que se relaciona em autorreferência com aquilo que lhe é externo. Nos modos anteriores, muito diferentemente, trata-se de um centro difusor, mas não de uma atividade em que se pode notar autorreferência, ainda que incipiente.

${ }^{15}$ Para abordar a caracterização da subjetividade nas plantas e nos animais, partirei tanto das análises de Hegel da própria Filosofia da Natureza, quanto de alguns trechos da "Introdução" da Filosofia do Espírito, onde Hegel opera uma análise retrospectiva a fim de averiguar a gênese da subjetividade do espírito a partir do desenvolvimento subjetivo da natureza. Trata-se, especificamente, do parágrafo 381 da Enciclopédia. O fato de Hegel elaborar esta análise retrospectiva, para mim, já indica que o autor concebe que a subjetividade do espírito possui sua gênese real na Natureza.
} 
parte de uma totalidade maior como ocorria antes na natureza geológica (Cf. HEGEL, 1997, § 337, adendo). A individuação do vegetal ocorre através de sua corporificação, da divisão de sua unidade em diferentes membros: caule, folhas, flores etc. Desse modo, podemos já observar nas plantas "um centro expandido na periferia, uma concentração das diferenças, um desenvolverse de dentro para fora, uma unidade diferenciando-se a si mesma" (Hegel, 1995, §381, adendo). Esta unidade é, propriamente, a semente, o gérmen da planta, e ele, de certo modo, permanece uno na linha do desenvolvimento, crescimento e auto-diferenciação do vegetal. Isso significa que a planta tem, pois, uma interioridade articulada em suas diferenças e mudanças e que ela é, portanto, orgânica em sua constituição. Somente por isso, porque a planta é em si um tipo de organismo vivo, articulado internamente, é que ela tem impulso e pode crescer de dentro para fora, a partir de um télos interno próprio. É neste sentido, pois, que Hegel afirma que a planta já é subjetividade frente ao mundo externo, pois é interioridade individual viva e orgânica.

Mas, segundo Hegel, a subjetividade da planta não é ainda completamente realizada. Pois, apesar de a planta dividir-se em membros e procurar penetrá-los, ela não os domina, mas permanece impotente ante os mesmos (Cf. HEGEL, 1997, § 337, adendo). Logo, “cada planta é por isso apenas uma multidão infinita de sujeitos, e a conexão pela qual eles aparecem como um sujeito é somente superficial" (idem). Cada parte da planta é, dessa maneira, uma repetição dela; de tal modo que, se eu retiro da mesma um pedaço de galho com folhas e o planto, posso ter, novamente, a mesma planta. Além disso, o vegetal encontra-se ainda atraído e curvado à exterioridade, uma vez que passa a vida à procura de luz solar para realizar o processo de fotossíntese. A unidade subjetiva do organismo vegetal não é ainda, portanto, acabada, plenamente individualizada no interior de suas diferenças.

Nos animais, temos, por outro lado, uma subjetividade concreta, mais plenamente realizada. Hegel chega a dizer - como já apontei acima na nota 9 - que na vida animal temos o início efetivo do idealismo absoluto, ou seja, da plena articulação entre seu corpo orgânico e o mundo natural (Cf. HEGEL, 1997, § 350, adendo). Vejamos abaixo alguns aspectos da subjetividade animal.

Antes de tudo, é importante destacar que no corpo vivo orgânico - tanto das plantas, como vimos, quanto dos animais - encontramos um télos interno. Este télos é próprio apenas dos seres vivos e Hegel o destaca tendo em mente a anterior caracterização kantiana da Crítica 
da Faculdade de Julgar, onde Kant pensava o vivo como fim para si mesmo ${ }^{16}$. Assim, para Hegel, a vida é seu próprio fim, um autótelo. A teleologia interna é própria do organismo, onde cada membro, ou cada órgão, é meio e fim para a totalidade do sistema, algo suposto e engendrado pelo todo mesmo, não podendo sequer ser pensado como independente $-\mathrm{e}$ isso pode ser pensado tanto no nível das plantas, como no dos animais. O télos interno, além disso, tem o caráter de reflexão, por meio da qual, o todo orgânico volta-se para si mesmo, se conservando em meio às diferenças. Esta finalidade própria ao organismo vivo tem a função específica de fazer com que cada corpo tenha a si mesmo como fim, ou seja, que vise sempre a sua auto-regulação e autoconservação. Sob este aspecto, Wandschneider afirma que todo organismo vivo possui um sistema de auto-regulação, pelo qual ele se afirma enquanto vivo e se distingue de outros sistemas naturais. Assim, diferentemente de um organismo vivo, por exemplo, o ser do átomo de Hélio não se preocupa com seu próprio ser - por isso, além de faltar-lhe a auto-regulação, falta-lhe a auto-instância, ou o seu auto-relacionamento interior (Cf. WANDSCHNEIDER, 2010, p. 56). Por meio desta esfera de autoconservação e auto-instância, próprias ao télos interno, de que fala Wandschneider, o organismo vivo se põe como interioridade, como subjetividade que se autorrefere e se autoconstitui - tal como vimos ser o caso com o conceito subjetivo lógico que se põe internamente em um movimento de autorreferência.

Os animais, neste contexto, desenvolvem maximamente o fim interno, de maneira que todo o seu organismo volta-se para a auto-regulação e conservação de seu corpo e toda atividade que empreende na exterioridade visa, em última instância, a sua sobrevivência. Assim, encontramos no animal uma totalidade orgânica praticamente perfeita, onde cada membro é causa e efeito dos demais, seu meio e fim, de modo que nenhum órgão aparece como autônomo, mas é, antes, uma determinidade ideal do todo. Por isso, "no corpo animal o 'fora-um-do-outro' se mostra em sua total inverdade" (Hegel, 1995, § 381, adendo). Nesta medida, todo elemento que adentra no corpo do animal é imediatamente submetido à harmonia auto-reguladora de seu organismo, que visa sempre à sua auto-manutenção. Por outro lado, ao atuar no mundo em busca, por exemplo, de alimento, o animal lida com a exterioridade como com a um outro que deve ser submetido à sua finalidade própria, ao seu télos interno (Cf. HEGEL, 1997, § 352, adendo). As plantas, diferentemente, apesar de possuírem o télos interno e visarem à sua auto-

\footnotetext{
${ }^{16}$ Acerca da influência da concepção de Kant na compreensão hegeliana sobre o conceito de teleologia ver Silva (2018) "Vida e finalismo na Ciência da Lógica", onde a autora trata sobre a origem do conceito de teleologia em Hegel e da diferença mais específica entre teleologia interna e externa.
} 
regulação e auto-manutenção, também se deixam, por outro lado, sucumbir à determinação e modificação da exterioridade, não sendo, pois, completamente senhoras de seu télos interno ${ }^{17}$.

Devido a esta perfeita configuração autotélica interna do corpo animal, é possível que emerja a sensação. Conforme Hegel, "a sensação é justamente essa onipresença da unidade do animal em todos os seus membros, os quais comunicam imediatamente cada impressão ao todo uno, que no animal começa a vir-a-ser para si” (Hegel, 1995, § 381, adendo; o grifo é meu). É interessante destacar nesta passagem que justamente pelo fato de o animal se configurar como corpo orgânico é possível que ele possua sensação, que ele sinta. Pois, se o animal possuísse vários membros e partes que não se comunicassem entre si, mas que apenas subsistissem independentemente, ele não sentiria no todo de seu ser um estímulo - seja de dor, ou de prazer. Ora, ao sentirmos uma dor no pé, por exemplo, a dor deste membro específico é sentida como minha dor (do meu ser em sua totalidade, em seu “ser para si"), e não como dor de algo distinto de mim mesma. Assim, como Hegel sustenta, apenas porque há uma onipresença do animal em todos os seus membros é que ele pode sentir, ou seja, somente porque o animal é um todo cíclico, uma teia orgânica em que cada parte é submetida à totalidade é que ele tem sensação. Segundo Hegel, a sensação é a riqueza mais alta da natureza, pois tudo aí está contido. A sensação é, assim, o ponto determinável que unifica o sujeito consigo por meio de uma diferença particular introduzida no interior de sua universalidade inicialmente indiferente $(\mathrm{Cf}$. HEGEL, 1997, § 351, adendo).

Destarte, o que podemos retirar de mais relevante desta constatação de Hegel é que o corpo vivo do organismo animal, ou seja, este elemento, antes de tudo, material, é condição para a emergência da idealidade do sentir, ou seja, da subjetividade animal em seu mais alto e sutil nível. Sob este aspecto, a sensação pode ser pensada como a unidade, por um lado, do complexo corpóreo - que responde fisiologicamente aos estímulos, sejam eles internos, ou externos - e, por outro lado, do elemento ideal do "para si”, do "estar consigo mesmo sentindo" da alma animal. A sensação é, portanto, este ponto de intercruzamento, de intersecção entre corpo e alma na natureza ${ }^{18}$. Nesta medida, Rand fala que a sensação é função sensorial do

\footnotetext{
17 “O organismo animal é o microcosmo, o centro da natureza feito para si, onde toda a natureza inorgânica se recapitulou e se idealizou: isto tem de expô-lo a apresentação mais pormenorizada. Enquanto o organismo animal é o processo da subjetividade, o de relacionar consigo mesmo na exterioridade, encontra-se aqui pela primeira vez a restante natureza como uma de-fora, pois o animal[ico] nesta relação se mantém para o exterior. Como porém a planta é atraída para fora, sem se manter verdadeiramente na relação ao outro, por isso para ela a restante natureza ainda não é tida como uma outra. - A vida animal é, como seu próprio produto, como fim-de-si-mesma [autotélica], fim e meio juntamente" (Hegel, 1997, § 352, adendo).

${ }^{18}$ Segundo Wandschneider, na sensação encontramos a convivência de uma situação externa junto a uma avaliação interna. Ele dá o exemplo da experiência de uma lâmina quente de fogão, onde existe a situação externa - a
} 
sistema nervoso do organismo do animal; contudo, de outra parte, ela traz a atividade do animal para um foco, para o sentir preciso - o que constitui justamente a subjetividade. "Assim - afirma ele - a unidade subjetiva do organismo animal, tal como manifestada na função do sistema nervoso, depende que a atividade deste sistema efetive o sentimento de si do animal" (Rand, 2010, p. 42). Consequentemente, a sensação em Hegel não pode ser interpretada apenas de modo fisicalista, mas ela deve ser vista também como a determinação apropriada da idealidade e da emergência da subjetividade (Cf. WANDSCHNEIDER, 2010, p. 63).

Além do télos interno e da sensação como momentos importantes da subjetividade animal, podemos considerar também a característica de auto-mobilidade do animal que se liga intimamente à sua capacidade de instinto (Instinkt). Segundo Hegel, na interioridade subjetiva do animal reside o fato de que ele "é determinado por si mesmo, de dentro para fora, e não simplesmente de fora" (Hegel, 1995, § 381, adendo). Ora, nas plantas não encontramos esta capacidade de autodeterminação e movimento, uma vez que sua interioridade não era plenamente constituída, mas, antes, encontrava-se também submetida à exterioridade. Nos animais, diferentemente, existe, de maneira incipiente, esta alta habilidade de determinar-se e mover-se na exterioridade. Hegel afirma: “A subjetividade do animal encerra uma contradição, e o impulso de se conservar mediante a suprassunção desta contradição; autoconservação que é o privilégio do ser vivo e, num grau mais alto, o privilégio do espírito" (Hegel, 1995, § 381). O ser que sente é, pois, determinado, possui no interior de si uma diferenciação particular ${ }^{19}$. No caso dos animais, esta diferenciação particular é precisamente a sensação e o animal tem, consequentemente, o impulso de resolver esta diferenciação. Para melhor elucidar tal reflexão de Hegel, podemos pensar no caso da fome, ou sob uma caracterização mais geral, da falta e carência que sente o animal e que é inerente, inclusive, ao ser do espírito. Assim, com base nesta diferença posta em seu interior, o animal se impulsiona a resolvê-la praticamente na natureza exterior, buscando, pois, se alimentar, saciar sua falta a fim de - pelo seu télos interno, ou instinto - se autoconservar, graças ao que é consumido.

Com efeito, a busca do animal para resolver sua contradição interna só é possível porque o animal possui a capacidade de se locomover. As plantas, em contraste, são absolutamente

\footnotetext{
temperatura registrada objetivamente pelos sensores - que se liga, além disso, a uma percepção interna produzida pelo Si (Selbst), donde teremos, consequentemente, a sensação de dor, de quente etc. (Cf. WANDSCHNEIDER, 2010, p. 60). Pela sensação, portanto, o corpo animal não dá uma mera resposta cega, mecânica, aos estímulos externos, mas ele sente, ele produz uma idealidade em seu interior. Este exemplo de Wandschneider é, pois, ilustrativo para pensarmos nesta dupla face da sensação: corpórea e ideal.

${ }^{19}$ Como vimos, o momento da particularidade constitui um momento da totalidade subjetiva do conceito lógico e, como tal, é pertinente também às formas reais de subjetividade.
} 
fixadas no lugar e, por isso, encontram-se em grande parte submetidas à exterioridade da natureza, sem conseguir cumprir completamente seu impulso interno autonomamente.

\begin{abstract}
O animal, como singularidade que se refere a si, possui esta singularidade do lugar, mas não como algo que lhe seja determinada de fora; porém, como singularidade voltada para si (...). O animal não sai para fora da universal determinação da singularidade do lugar, mas este lugar é posto por ele. Justamente por isso a subjetividade do animal não só é diferente da natureza exterior, mas ele próprio se distingue da mesma; e esta é uma distinção altamente importante, a saber: o pôr-se como a pura negatividade própria deste lugar e deste lugar etc. (Hegel, 1997, § 351, adendo).
\end{abstract}

Finalmente, recapitulo os traços que compõem a subjetividade do organismo animal que foram por mim aqui abordados. $\left(1^{\circ}\right)$ o animal possui um télos interno que se atualiza em seu interior visando sua auto-regulação e auto-afirmação como interioridade frente ao exterior; $\left(2^{\circ}\right)$ o animal tem sensação, dado que seu organismo é perfeitamente articulado, de modo que ele pode sentir a dor ou o prazer de um membro específico em sua totalidade, ou seja, ele é "para $s i$ ” em sua particularidade e $\left(3^{\circ}\right)$ o animal possui um impulso e, através de seu instinto, se move como sujeito na exterioridade em busca de se saciar. Portanto, o animal possui, para Hegel, uma interioridade constituída, um "si que é para si”, ou seja, o animal, como afirma Hegel, é universalidade para si essente. "Assim, existe no animal a unidade verdadeiramente subjetiva, uma alma simples, a infinitude da forma em si mesma, que está exposta na exterioridade do corpo, e esta de novo em conexão com uma natureza inorgânica, com um mundo exterior" (Hegel, 1997, § 350, adendo; o grifo é meu).

Diante desta breve análise sobre o organismo vivo na natureza, proponho uma divisão do conceito de subjetividade no interior da Filosofia do Real de Hegel: na Natureza, podemos identificar a subjetividade como "subjetividade vital", ao passo que no Espírito, trata-se da “subjetividade espiritual”, ou do espírito subjetivo. Mas, uma questão imediatamente me surge: até que ponto posso afirmar que o conceito de subjetividade na Filosofia do Espírito não seria diretamente influenciado por esta base orgânica e vital da subjetividade da Filosofia da Natureza? Até que ponto há uma continuidade entre estas duas esferas que se concretiza também na continuidade do conceito de subjetividade? Apesar do conceito de subjetividade do espírito ser profundamente amplo e merecer, desse modo, uma análise mais detalhada, estou pensando aqui apenas especificamente na incipiente subjetividade do espírito, que é a alma (Seele). Pois, conforme o próprio Hegel, a alma configura o aspecto universal e natural do espírito em sua autorrelação consigo e também com a exterioridade (Cf. HEGEL, 1995, § 387). 
Desse modo, em alguma medida é possível ponderar se há alguma conservação significativa das determinações do conceito de subjetividade animal no interior da alma do espírito. Além disso, é preciso considerar também que o sistema de Hegel se mostra, como já apontei atrás, como um "círculo de círculos" e, ademais, cada círculo singular "rompe também a barreira de seu elemento e funda uma esfera ulterior" (Hegel, 2005, § 15). Ou seja, cada parte, ou círculo do sistema não é desvinculado do outro e há, além disso, a auto-posição de cada esfera, que põe e funda a ulterior. Há, por conseguinte, um processo continuado e cíclico entre as partes da filosofia, de modo que, inclusive, podemos compreender que existe uma inter-reciprocidade entre os conceitos tratados em cada "círculo". É desse modo, por exemplo, que o conceito lógico de subjetividade é retomado em sua estrutura formal de autorreferência universal e ideal na Filosofia do Real, como vimos mais acima. Nesta medida, analiso em seguida a passagem da Filosofia da Natureza para a Filosofia do Espírito, me centrando especificamente na emergência da alma do espírito a partir da subjetividade animal.

\section{A passagem da subjetividade animal para a alma do espírito}

Segundo Richard Winfield (2014) em seu livro Hegel and Mind, o espírito advém da natureza, havendo entre ambas as esferas uma continuidade estrita:

\footnotetext{
A mente, sem adicionais qualificações, sobrevém da natureza em seu mais completo desenvolvimento, como organismo animal e, como tal, a mente é uma unidade abrangente que contém esta realidade como sua constituinte. Isto significa que a mente minimamente vem da própria natureza e não é produto de qualquer processo mental, relacionando-se com ela [com a natureza] sem nenhum intermediário e incorporando-a sem, contudo, modificar seu conteúdo (Winfield, 2014, p. 8; o colchete é meu; a tradução é minha).
}

Esta afirmação contém uma tese muito forte, qual seja, a de que a mente provém da natureza, tendo como seu ponto de partida justamente o organismo animal, sem que, contudo, modifique em nada o seu conteúdo. Winfield utiliza aqui o termo "mind" para se referir ao espírito subjetivo. A partir disso, poderíamos pensar: a mente humana, ou melhor, o espírito, não seria algo fundamentalmente racional? Nesta medida, como o espírito pode provir da própria natureza, incorporando-a, sem modificar seu conteúdo? Estas são perguntas importantes de se fazer e Hegel parece não ter se furtado a elas. Por isso, como vimos nos tópicos anteriores, 
nosso autor procurou reconstituir a origem do conceito de subjetividade na natureza e aborda, inclusive, esta gênese no início de sua Filosofia do Espírito. Deste ponto de vista, a tese de Winfield exposta acima pode não soar tão estranha, pois ele está afirmando nada mais do que o fato da mente humana provir de um certo desenvolvimento da natureza; ou seja, ela não é uma novidade completa na história dos seres, de outro modo, já se ouvira falar antes de subjetividade no mundo animal ${ }^{20}$. Assim, o ponto de partida preciso do surgimento do espírito, na filosofia hegeliana, é a subjetividade do organismo animal. Esta última constitui o ponto mais alto a que a natureza pôde alcançar, como vimos, e é justamente dele que emerge a alma humana.

A respeito da discussão sobre a emergência da alma humana, ou de modo mais geral, do espírito, Wandschneider afirma, em uma perspectiva interessante, que apesar do organismo possuir um sentido inteiramente material de um sistema físico-químico, ele é, outrossim, o ponto de partida para a emergência ${ }^{21}$ do psíquico. Assim, segundo ele, somente sob o ponto de vista da emergência, podemos pensar o surgimento do espírito, pois, conforme afirma:

O conceito de emergência, oriundo da teoria dos sistemas, possui aqui uma função chave. Todavia, não se trata da evocação de uma fórmula mágica. Pela emergência, torna-se compreensível o surgimento de propriedades de sistemas que são completamente novas em relação às propriedades de formas naturais primitivas (Wandschneider, 2010, p. 69; o grifo é meu).

Em outras palavras, pela lente do conceito de emergência, podemos observar como plenamente conciliáveis, por um lado, características fisiológicas do organismo como constituintes do corpo e, por outro, propriedades mentais, ideais, racionais, como constituintes do espírito. Isso porque há uma certa hierarquia dos níveis, uma certa gradação em que, lentamente, novas propriedades se desenvolvem a partir de sistemas inferiores. Traduzindo para o enfoque da filosofia hegeliana: a partir dos elementos propriamente desenvolvidos na Natureza, o Espírito emerge trazendo à luz novas atribuições, antes impensadas no sistema inferior da pura exterioridade. Assim, conclui Wandschneider, o ponto central é que algo ideal

\footnotetext{
${ }^{20}$ Com esta perspectiva, ainda que me pareça bastante interessante, estou longe de querer tocar na questão do evolucionismo natural como dinâmica produtora do cérebro humano e, consequentemente, da possibilidade da mente, tal como abordada pelos estudos da Neurociência em correlação com a Biologia Evolutiva. Foco-me tão somente no âmbito das discussões próprias da filosofia de Hegel, que está interessado no conceito da emergência do espírito.

${ }^{21} \mathrm{O}$ conceito de emergência é bastante discutido em Filosofia da Mente e nas Ciências Cognitivas de um modo geral e sua definição, em síntese, gira em torno da problemática da origem da mente: se ela provém e se reduz aos seus aspectos materiais, incluindo as ligações neuronais, ou se, por outro lado, ela emerge deste sistema material sem, por isso, se reduzir às suas características, ainda que as pressuponha.
} 
pode surgir de algo material (Cf. WANDSCHNEIDER, 2010, p. 70) ${ }^{22}$.

Consequentemente, voltando-nos para a citação que abre o presente tópico, é perfeitamente plausível pensar, com Winfield, que a mente humana provenha do organismo animal. Mas, cabe destacar, será que ela não 'modifica em nada o seu conteúdo', tal como ele afirma?

De fato, o próprio Hegel alude ao conceito aristotélico das três almas para sustentar que há uma tríplice divisão do anímico e, por conseguinte, diferenças, entre a subjetividade vegetal, a animal e a humana (Cf. HEGEL, 1997, § 351, adendo). Hegel fala, ademais, ainda na esteira de Aristóteles, em um certo processo cumulativo entre estes três níveis pelo qual a alma animal possui também atribuições do vegetal (como sua relação à luz, à água e etc.); assim como a alma humana possui também a sensação provinda dos animais, ainda que acrescente a esta o pensamento. Para Aristóteles, é muito claro este processo cumulativo entre as três almas. No entanto, mais do que isso, para o estagirita, não se trata apenas de uma justaposição das faculdades anímicas em cada novo nível deste processo. De outro modo, em um nível mais elevado da realidade anímica, por exemplo, nos homens, a faculdade nutritiva (aquela atividade básica já nos vegetais) e a sensitiva interagem e são afetadas pela capacidade discursiva e do pensamento (Cf. ARISTÓTELES, 2011, 414b25-30)23.

Nesta medida, apesar de provir do mundo natural e, mais especificamente, da subjetividade orgânica do animal, a alma humana guarda suas especificidades e podemos dizer que, de certo modo, suspende (aufheben) a alma do organismo animal. Curioso ressaltar a particularidade própria do verbo suspender na filosofia hegeliana. Ele possui três acepções gerais: (a) em um primeiro momento ele significa negação; (b) em um segundo momento, conservação e, enfim, (c) elevação. Do que se segue que a alma humana primeiramente nega a alma animal; mas em que sentido ela negaria? À qual atribuição precisa se refere esta negação? Neste caso, podemos pensar que trata-se da negação dos instintos puros e simples do animal, pois no caso do humano, tem-se a atribuição da liberdade, da livre e consciente autodeterminação e não a perseguição cega e irrefletida dos instintos. No que tange ao processo de conservação - segundo movimento do verbo aufheben - trata-se, podemos pensar, do

\footnotetext{
${ }^{22}$ Mais uma vez friso que este ponto da discussão, em Hegel, sobre a emergência da idealidade da alma humana a partir da alma animal, não se refere a uma problemática evolucionista, dado que, em Hegel, como sabemos, o sistema se desenvolve a partir do movimento dialético do conceito (Cf. HEGEL, 1997, § 249). Hegel está tratando, portanto, do conceito de natureza, do conceito de alma animal e do conceito de alma humana - e não elaborando uma História Natural.

${ }^{23}$ A respeito da influência do conceito de alma em Aristóteles na filosofia hegeliana ver Os atos do Espírito (2004) de Bourgeois.
} 
elemento da sensação, do elemento do télos interno próprio à constituição do organismo e à sua autoconservação, ainda que, em um terceiro momento, a alma humana eleve todas estas determinações, conjuntamente, ao nível do espírito, mesclando-as com o elemento do pensamento e da liberdade. Nesta perspectiva, não podemos falar de saltos, de lacunas ou abismos que possam existir entre o mundo natural e o mundo humano. Antes, pode-se pensar que existe um desenvolvimento gradual, onde passa-se da alma animal para a alma humana. Neste sentido, Pinkard afirma:

A proposta de Hegel é que o movimento de nossa vida animal para nossa vida completamente auto-consciente parece ser concebida em termos de estágio, ligando o tipo de fim [Zweeck] característico da vida animal e o caráter racional da vida consciente. E estes estágios não devem ser interpretados como estágios separados no interior da vida auto-consciente (como se os últimos estágios pudessem existir à parte dos primeiros). (...). Consequentemente, nós temos que pensar como tal consciência humana incorpora no interior de si mesma este tipo de vida animal como uma série de estágios que medeia cada outro (Pinkard, 2013, p. 27; a tradução é minha).

A proposta de Pinkard é, portanto, investigar a influência da "subjetividade vital" no interior da "subjetividade espiritual", pesquisar como se passa do nível da subjetividade natural para o nível da subjetividade racional. Como se vê, não é um espanto na literatura recente de investigação sobre a filosofia hegeliana, o forte grau de naturalismo presente nas concepções de Hegel acerca da subjetividade na Filosofia do Real. Antes, pudemos notar que há uma defesa comum da noção de continuidade do mundo natural para o mundo do espírito e, mais especificamente, da alma animal para a alma humana. A este respeito, é interessante ver também a leitura de Robert Pippin no artigo "Hegel, Freedom, The Will. The Philosophy of Right: $\S \S 1-33 "$ (1997), que sustenta uma leitura "holista especulativa" da Enciclopédia hegeliana. Segundo Pippin, devemos pensar sob um viés compatibilista, e não dualista e excludente, os termos natureza e espírito, necessidade e liberdade, matéria e idealidade, corpo e alma na filosofia de Hegel, pensando a relação natureza e espírito como um verdadeiro monismo ${ }^{24}$.

Para finalizar, cabe apontar que na "Antropologia” da Filosofia do Espírito, Hegel trata da alma segundo inúmeras características que não encontramos na consideração sobre o animal. Nós iremos nos deparar nesta seção com temas relativos a mudanças das fases da vida, da

\footnotetext{
${ }^{24}$ Para uma leitura divergente desta "naturalista" a respeito da Filosofia do Espírito de Hegel, ver PATTEN, Hegel's Idea of Freedom (2002). Patten sustenta que Hegel segue a consideração kantiana na filosofia moral e que encontramos em Hegel uma cisão entre naturalidade e racionalidade.
} 
diferença entre as raças, da relação mãe e feto, dos sonhos, da loucura e até mesmo do hábito. Estas indicações são importantes para ressaltar que trata-se, especificamente, de uma consideração sobre a alma humana, daí o título "Antropologia", e que Hegel quer frisar que apesar da base orgânica e vital da alma, ela já contém inscrita em si mesma o sinal do espírito, ou seja, já guarda em si certa elevação psíquica frente ao mundo natural.

Desse modo, ao longo da "Antropologia", em mais de um momento, podemos observar esta especificação da alma humana em relação à alma animal e encontrar já a marca do espírito, ou seja, do pensamento e da vontade na naturalidade da alma. Assim, quando Hegel fala da sensação, indica que esta pertence tanto ao animal, quanto ao espírito, e que ela consiste em uma forma de auto-relacionamento, ou autorreferência da alma humana consigo mesma. Contudo, na alma humana, a sensação pode ser elevada ao pensamento e sair de sua simples imediatidade corpórea (CF. Hegel, 1995, § 400). Além disso, pelo hábito, por exemplo, mesmo que o homem esteja no modo de uma existência natural, já encontramos a elaboração de seus conteúdos corpóreos e podemos identificar a marca do espírito até mesmo na simples atividade humana de manter-se em postura ereta (Cf. HEGEL, § 410). Desse modo, ainda que a alma humana, enquanto primeiro aspecto da subjetividade do espírito, esteja em completa unidade com o corpo e se relacione a si mesma idealmente com o corpo e por meio dele ${ }^{25}$, já podemos encontrar processos espirituais mais "elevados", ou seja, pertinentes à forma do pensamento e da vontade, nesta forma natural do espírito. Isso porque, ainda que o espírito subjetivo se divida em alma, consciência, pensamento e vontade, como já apontei atrás, estes aspectos de sua subjetividade não são justapostos um ao outro, mas, diferentemente, eles se ligam intimamente e se inter-conectam no interior da totalidade do espírito. Hegel deixa isso claro no parágrafo 380 da "Introdução" da Filosofia do Espírito; segundo ele, a natureza concreta do espírito "traz consigo para a consideração esta dificuldade peculiar de que os graus e determinações particulares do desenvolvimento de seu conceito não permanecem, ao mesmo tempo, como existências particulares, para trás e em contraposição a suas figurações mais profundas” (Hegel, $1995, \S 380)$.

Por fim, uma questão interessante é pensar como a base orgânica natural, que provém da natureza como "subjetividade vital", permanece presente nestas esferas superiores de

\footnotetext{
${ }^{25}$ Hegel discute sobre a unidade entre corpo e alma no parágrafo 389 de sua "Antropologia". Lá, ele critica a concepção da Antiga Psicologia Racional que concebia alma e corpo em oposição fixa. Para Hegel, diferentemente, corpo e alma constituem inicialmente uma unidade originária, que consiste justamente no conceito de alma, que, para Hegel, é a base e a substância do espírito em seu posterior desenvolvimento como consciência, pensamento e vontade. Pode-se pensar o conceito de alma, na filosofia hegeliana, nesta perspectiva, sob uma significação única como alma-corpo, enquanto uma autorrelação da idealidade corpórea a si mesma.
} 
subjetivação do espírito, ou melhor, como o corpo vivo animado exerce influência na constituição da consciência, pensamento e vontade - momentos estes marcados pela pureza, formalidade, liberdade e racionalidade. Equacionar estas relações e inter-conexões, e inclusive a questão da relação corpo-mente no interior da vida mais elevada do espírito, é uma instigante tarefa a ser percorrida na linha das sugestões de Terry Pinkard, como vimos acima. No entanto, o presente trabalho tinha o intuito apenas de reconstruir a gênese lógica do conceito de subjetividade, procurando ainda percorrer o desenvolvimento deste conceito como vida na Natureza e, depois, a passagem da subjetividade animal para o primeiro estágio da subjetividade do espírito, que é aquele da alma.

\section{Referências bibliográficas:}

ARISTÓTELES. De Anima. São Paulo: EDIPRO, 2011.

BOURGEOIS, B. Hegel Os atos do Espírito. São Leopoldo: Editora Unisinos, 2004.

FERRARIN, A. Thinking and I. Hegel and the Critique of Kant. Illinois: Northwestern University Press, 2019.

FERRER, D. A Gênese do Significado. Introdução ao Pensamento de Hegel. Portugal: Fundação Eng. António de Almeida, 2016.

HEGEL, G.W.F. Ciência da Lógica. 1. A Doutrina do Ser. Petrópolis/RJ: Editora Vozes, 2017. Ciência da Lógica. 3. A Doutrina do Conceito. Petrópolis/RJ: Editora Vozes, 2018. . Enciclopédia das Ciências Filosóficas em Compêndio (1830). Volume II. A Filosofia da Natureza. São Paulo: Edições Loyola, 1997.

Enciclopédia das Ciências Filosóficas em Compêndio (1830). Volume III. A Filosofia do Espírito. São Paulo: Edições Loyola, 1995.

Príncipes de la Philosophie du Droit ou Droit Naturel et Science de L'État en Abgrégè. $4^{\text {a }}$ edição. Paris: Libraire Philosophique J. Vrin, 1993.

HÖSLE, V. O Sistema de Hegel, O Idealismo da Subjetividade e o Problema da Intersubjetividade. São Paulo: Edições Loyola, 2007.

KANT, I. Crítica da Razão Pura. 7ª edição. Lisboa: Fundação Calouste Gulbenkian, 2010.

PATTEN, A. Hegel's idea of freedom. New York: Oxford University Press, 2002.

PIPPIN, R. Hegel, Freedom, The Will. The Philosophy of Right: $\$ \S 1-33$. Grundlinien der Philosophie des Rechts, Berlin: Akademie Verlag, 1997. 
Hegel's Realm of Shadows: Logic as Metaphysics in "The Science of Logic". University of Chicago Press, 2019.

PINKARD, T. Hegel's Naturalism: mind and nature. Oxford: Oxford USA Professio, 2012.

PERTILlE, J. P. Faculdade do Espírito e Riqueza Material: Face e Verso do Conceito de "Vermögen" na Filosofia de Hegel. 2005. Disponível em: https://lume.ufrgs.br/handle/10183/5491. Acesso em: 10/07/2019.

RAND, S. Subjetividade Animal e o Sistema Nervoso na Filosofia da Natureza de Hegel. Revista Eletrônica Estudos Hegelianos. Recife, v. 7, n. 12, jan. 2010. Disponível em < http://www.hegelbrasil.org/reh_2010_1_art2.pdf>. Acesso em: 16 fev. 2016.

SILVA, M.Z.A. Vida e finalismo na Ciência da Lógica. Campinas, SP: Editora Phi, 2018.

WANDSCHNEIDER, D. Formas Elementares do Psíquico: um esboço teórico-sistemático a partir da interpretação hegeliana do organismo. Revista Eletrônica Estudos Hegelianos. Recife, v. 7, n. 12, jan. 2010. Disponível em <http://www.hegelbrasil.org/reh_2010_1_art3.pdf $>$. Acesso em: 16 fev. 2016.

WINFIELD, R.D. Hegel and Mind. Rethinking Philosophical Psychology. Georgia: Palgrave Macmillan, 2014. 